\title{
PILHAS DE COMBUSTÍVEIS MICROBIANAS UTILIZADAS NA PRODUÇÃO DE ELETRICIDADE A PARTIR DE REJEITOS ORGÂNICOS: UMA PERSPECTIVA DE FUTURO*
}

\author{
Silvio Rachinski, Ademir Carubelli, Ana Paula Mangoni e Antonio S. Mangrich* \\ Departamento de Química, Universidade Federal do Paraná, CP 19081, 81.531-990 Curitiba - PR, Brasil
}

Recebido em 28/11/09; aceito em 19/4/10; publicado na web em 24/8/10

\begin{abstract}
MICROBIAL FUEL CELLS USED IN THE PRODUCTION OF ELECTRICITY FROM ORGANIC WASTE: A PERSPECTIVE OF FUTURE. In this review is presented an innovative technology for use of animal and vegetable waste with high pollution levels in microbial fuel cell (MFC) as an alternative to waste remediation and simultaneously producing electricity and fertilizer for agriculture. A brief history of MFC, the studies about the electron transfer mechanisms, discussion of the biological nanowires in bacteria and the use of chemical mediators or carriers of electrons are explained. The factors influencing the performance of MFCs, the application in waste and sewage treatment and power generation are also discussed.
\end{abstract}

Keywords: microbial fuel cells; bacteria and electricity; energy from organic waste.

\section{INTRODUÇÃO}

\section{Células de combustível microbianas}

"A desintegração de compostos orgânicos por microorganismos é acompanhada pela liberação de energia elétrica". M. C. Potter, 1912. ${ }^{1}$

Cientistas e engenheiros de diferentes áreas do conhecimento buscam desenvolver novas tecnologias para dar utilidade aos rejeitos de biomassa e lixos em geral, atendendo também às crescentes necessidades globais de energia. ${ }^{2}$ Nesses trabalhos, surgem três questões principais: a ambiental, a econômica e a tecnológica propriamente dita, no sentido de poder suprir as demandas crescentes de energia. As células combustíveis microbianas $(M F C)$ geradoras de eletricidade atendem bem à primeira questão, e estudos estão sendo realizados para que atendam também a segunda e a terceira. ${ }^{3-5}$

No processo natural de degradação da matéria orgânica, uma das reações (bio)químicas envolvidas é a de oxidação, que ocorre de maneira anaeróbia, enquanto os elétrons são recuperados através de reações enzimáticas. ${ }^{6}$ Os elétrons podem ser armazenados em intermediários como NADH ou quinonas. Ao fim da cadeia respiratória, o destino dos elétrons pode ser o oxigênio molecular ou outro aceitador extracelular.

Uma MFC utiliza micro-organismos para catalisar a oxidação da matéria orgânica, gerando eletricidade, pela transferência de elétrons para um circuito externo, introduzido antes da etapa da redução de um aceitador de elétrons. ${ }^{7}$ Assim, uma MFC é um dispositivo capaz de converter energia química em energia elétrica, através de reações químicas catalisadas por micro-organismos.

As MFCs consistem basicamente de dois compartimentos, um deles anaeróbio, contendo o ânodo e um compartimento aeróbio com o cátodo. Estes dois compartimentos são normalmente separados por uma membrana que impossibilita a difusão de $\mathrm{O}_{2}$ para o interior da câmara anódica, mas permite a passagem dos prótons gerados nesta para a câmara catódica. Há, entretanto, outras configurações possíveis, as quais serão discutidas em momento oportuno.

No compartimento anaeróbio ocorre a oxidação do material

*e-mail: mangrich@quimica.ufpr.br

\# Dedicated to Professor Ademir Carubelli, recently deceased, for his contribution to this work. orgânico, com formação de $\mathrm{CO}_{2}$, prótons e elétrons. Como exemplo é apresentado, a seguir, o processo de oxidação da glicose gerando prótons e elétrons. ${ }^{7}$

$$
\mathrm{C}_{6} \mathrm{H}_{12} \mathrm{O}_{6}+6 \mathrm{H}_{2} \mathrm{O} \rightarrow 6 \mathrm{CO}_{2}+24 \mathrm{H}^{+}+24 \mathrm{e}^{-}
$$

Os prótons gerados migram para o compartimento aeróbio (câmara catódica) permeando através da membrana trocadora de prótons. Os elétrons produzidos são transferidos para o catodo através do circuito externo, e na superfície deste ocorre a redução do oxigênio à água.

$$
4 \mathrm{H}^{+}+\mathrm{O}_{2}+4 \mathrm{e}^{-} \rightarrow 2 \mathrm{H}_{2} \mathrm{O}
$$

Este fluxo de elétrons através do circuito externo gera uma corrente elétrica que pode ser mensurada e utilizada para realizar trabalho. A reação global da célula é a conversão do material orgânico biodegradável a dióxido de carbono e água, gerando eletricidade no processo. ${ }^{8-12}$

Assim, micro-organismos anaeróbios oxidam o material orgânico na câmera do ânodo, gerando dióxido de carbono, prótons e elétrons. Alguns micro-organismos se fixam ao eletrodo como um biofilme e os elétrons são transferidos diretamente para o eletrodo, fluindo em seguida para o cátodo; os prótons também são transferidos para a câmara do cátodo através da membrana permeável somente a prótons, sendo uma das mais conhecidas, a chamada membrana Nafion ${ }^{\circledR}$. A molécula de oxigênio atua então como aceitadora de elétrons, ocorrendo a sua redução e reação com os prótons para formar água. Além do oxigênio, outras espécies químicas, como os íons $\mathrm{Fe}^{3+}$, cumprem também a função de aceitadores de elétrons. ${ }^{11}$

Algumas espécies de bactérias já identificadas em MFCs montadas em laboratório são: Shewanella putrefaciens, Geobacter sulfurreducens, ${ }^{13}$ Geobacter metallireducens e Rhodoferax ferrireducens, ${ }^{14}$ as quais são normalmente encontradas em sedimento marinho ou fluvial, e também em esgotos. Culturas puras de bactérias, como Rhodoferax ferrireducens, ou Geobacter sulfurreducens, foram usadas para a preparação de MFCs, ${ }^{13,14}$ entretanto, o uso de culturas mistas, como as existentes em lodos de tratamento de esgoto, também já foi citado como material biológico eficiente. ${ }^{15,16}$ Quanto ao substrato orgânico, vários tipos já foram testados com sucesso em MFCs, tais como amido, ${ }^{17}$ glicose,${ }^{6,18}$ e esgoto doméstico. ${ }^{18}$ 


\section{Um breve histórico das células de combustíveis microbianas}

O primeiro relato científico correlacionando organismos vivos e eletricidade é atribuído a Luigi Galvani que, em 1790, realizou experiência na qual observou contração das pernas de rãs submetidas à descarga de corrente elétrica. Desta observação surgiu o termo bioeletricidade. Em 1911, Michael Cresse Potter, professor de botânica na Universidade de Durham, UK, demonstrou a liberação de energia elétrica quando bactérias $E$. coli atuavam sobre substrato orgânico. ${ }^{18}$

Em 1931 Cohen, um pesquisador de Cambridge, reavivou a ideia de Potter, descrevendo um grupo de células combustíveis biológicas capazes de produzir tensão de aproximadamente 35 $\mathrm{V}$ e corrente elétrica de $2 \mathrm{~mA} .{ }^{6}$ Durante muito tempo o tema foi visto apenas como curiosidade científica. Em 1960 as células combustíveis biológicas tornaram-se populares quando a empresa de exploração espacial dos Estados Unidos da América, NASA, mostrou interesse por elas. ${ }^{19} \mathrm{O}$ objetivo era gerar eletricidade concomitantemente com a degradação de resíduos orgânicos produzidos durante as viagens espaciais.

Em 1962 Rohrback projetou uma célula de combustível microbiana na qual Clostridium butyricum foi usada como catalisador na geração de hidrogênio através da fermentação da glicose.$^{20} \mathrm{Em}$ 1963, algumas células combustíveis biológicas estavam disponíveis comercialmente, sendo usadas como fonte de energia para rádios receptores e luzes sinalizadoras em alto mar, e outros dispositivos, no entanto não alcançaram sucesso comercial e logo desapareceram do mercado. ${ }^{19} \mathrm{Em} 1966$ foram apresentadas várias células combustíveis microbianas utilizando palha de arroz que, ligadas em série, produziram corrente elétrica de $40 \mathrm{~mA}$ com tensão de $6 \mathrm{~V} \cdot{ }^{21} \mathrm{Em}$ 1969, Yao e colaboradores demonstraram que a glicose pode ser usada como substrato para geração de eletricidade usando como catalisador negro de platina. ${ }^{22}$ No entanto, com o desenvolvimento bem sucedido de alternativas mais viáveis tecnicamente, como as células fotovoltaicas, houve rápido desinteresse pelas células combustíveis microbianas. Mais tarde, durante a crise do petróleo ocorrida na década de 80, renovou-se o interesse no desenvolvimento das MFCs. Poucos anos depois, Karube e colaboradores descreveram a geração de corrente elétrica de aproximadamente $300 \mathrm{~mA}$ a partir da Anabaena spp, utilizando uma MFC com ácido fosfórico como eletrólito. ${ }^{23}$ Bennetto e seu grupo de pesquisa têm feito notáveis contribuições para as MFCs, tendo desenvolvido células combustíveis microbianas mais eficientes usando diversos micro-organismos e sistemas mediadores, que são determinados compostos químicos, como quinonas e ferricianeto, que atuam como eficientes intermediários na transferência de elétrons. $\mathrm{O}$ uso de alguns mediadores apresenta desvantagens, como a necessidade de reposição constante e geração de resíduos tóxicos para os microorganismos. ${ }^{5}$ Recentemente, Chaudhuri e Lovley citaram que $R$. ferrireducens pode recuperar até $83 \%$ dos elétrons provenientes da oxidação da glicose na presença de $\mathrm{Fe}^{3+}$, sem uso de mediadores. ${ }^{13}$

Um dos motivos das MFCs não serem normalmente consideradas como parte do portfólio das energias é que esta tecnologia não está suficientemente bem desenvolvida a ponto de gerar quantidades substanciais de energia com relação custo/benefício apropriada. ${ }^{24}$ As pesquisas de 40 anos atrás sugeriam que as MFCs poderiam ser atualmente usadas em larga faixa de aplicações, como geradores elétricos individuais para residências ${ }^{6} \mathrm{e}$ como fonte de energia para dispositivos eletrônicos, ${ }^{6,25}$ barcos ${ }^{25}$ e robôs autossustentáveis. ${ }^{26}$ No entanto, ainda não houve avanços suficientes para permitir que todas essas aplicações fossem postas em prática. A única aplicação pensada, em curto prazo, para as MFCs é na sustentação de dispositivos de monitoração em locais remotos. ${ }^{27}$

\section{OXIDAÇÃO DO MATERIAL ORGÂNICO}

Para que ocorra a liberação de elétrons da matéria orgânica, com a atual tecnologia das MFCs, um processo anaeróbio precisa ser promovido no ânodo para causar um fluxo de elétrons proveniente da oxidação da matéria orgânica. A fermentação apresenta mecanismo bem conhecido para a oxidação anaeróbia da matéria orgânica e, recentemente, surgiram vários estudos sobre células de combustível microbianas utilizando somente micro-organismos fermentativos. Entretanto, a fermentação é um método pouco eficiente para a geração de eletricidade a partir da matéria orgânica, pois muitos dos elétrons retirados da matéria orgânica não reagem prontamente com os eletrodos, resultando em baixa eficiência. ${ }^{11}$

A oxidação efetiva de material orgânico de composição heterogênea utiliza produtos do metabolismo da fermentação de açúcares, aminoácidos e outros compostos para a efetiva transferência de elétrons para um aceitador de elétrons. ${ }^{24}$

Os análogos naturais disponíveis no ambiente que mais se assemelham aos eletrodos para o metabolismo microbiano são provavelmente óxidos de $\mathrm{Fe}^{3+}$, pois tanto os eletrodos como estes óxidos são receptores de elétrons insolúveis e extracelulares. A oxidação da matéria orgânica, acoplada à redução de íons $\mathrm{Fe}^{3+}$ em sedimentos, requer a cooperação de um consórcio de micro-organismos fermentativos e microorganismos redutores de $\mathrm{Fe}^{3+}$. Os micro-organismos redutores de $\mathrm{Fe}^{3+}$ (normalmente Geobacter spp.) metabolizam os produtos de fermentação e os compostos orgânicos que os micro-organismos fermentativos não metabolizam prontamente, oxidando-os a dióxido de carbono, com os óxidos de $\mathrm{Fe}^{3+}$ servindo como receptores de elétrons. ${ }^{28}$

Embora existam micro-organismos redutores de íons férricos capazes de oxidar completamente compostos fermentáveis, como açúcares e aminoácidos, convertendo-os em dióxido de carbono com a redução de óxidos férricos, são mais comumente encontrados consórcios de micro-organismos fermentativos e redutores de óxidos férricos, ${ }^{28} \mathrm{o}$ que é explicado por considerações termodinâmicas. Obviamente, para gerar eletricidade com a oxidação da matéria orgânica, consórcios cooperativos similares são requeridos, com a diferença de que o ânodo serve como receptor final de elétrons.

Em 1996, Lovley e colaboradores descobriram um novo e importante papel biológico das substâncias húmicas no ambiente. ${ }^{28} \mathrm{Nesta}$ função estão envolvidos fluxos de carbono e elétrons nos ambientes anaeróbios. Os micro-organismos oxidam os poluentes orgânicos transferindo os elétrons resultantes para os ácidos húmicos que se reoxidam reduzindo íons de $\mathrm{Fe}^{3+}$. Mangrich e colaboradores ${ }^{29}$ utilizaram íons férricos e radicais livres orgânicos de substâncias húmicas (SH) como ponta de prova de espectroscopia de ressonância paramagnética eletrônica (EPR) para avaliação do nível de poluição ambiental. O esquema na Figura 1 mostra a sequência de reações envolvidas.
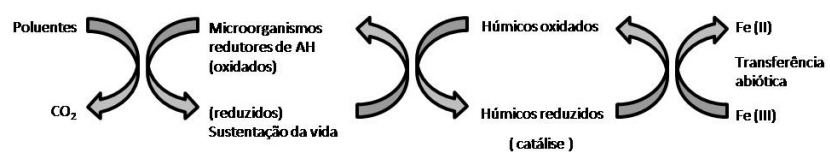

Figura 1. Esquema proposto para a função mediadora das SH na oxidação da matéria orgânica e redução do $\mathrm{Fe}^{3+}$

Deve-se ressaltar, no entanto, que poluente, no caso, significa qualquer composto orgânico, mesmo tido como não poluente pelos padrões atuais, mas que não seja evolutivamente próprio ao ambiente em causa. Uma bela lavoura cultivada com as regras do manejo do plantio orgânico será considerada material alienígena (poluição) e oxidada pelos micro-organismos nativos daquele local. 
A transferência de elétrons fornece energia para a manutenção dos sistemas de vida no local. As SH microbiologicamente reduzidas podem, então, transferir elétrons aos íons $\mathrm{Fe}^{3+}$ de forma abiota. No esquema acima não é mostrada a reoxidação anaeróbia dos íons $\mathrm{Fe}^{3+}$. Uma das reações que promovem essa oxidação é a da redução do íon sulfato a sulfeto. Assim, o cheiro de ovo podre em valas de esgoto a céu aberto não significa que tudo está perdido, mas que as bactérias estão trabalhando tentando limpar o ambiente. Nosso papel deve ser o de ajudá-las, parando de poluir. Essa é uma mensagem importante resultante do conhecimento científico que se contrapõe às notícias alarmantes sobre poluição dadas pela imprensa, que não animam as pessoas a agirem corretamente.

Concluiu-se que as substâncias húmicas mediam o aumento da velocidade de oxidação da matéria orgânica (MO) acoplada à redução de $\mathrm{Fe}^{3+}$ em solos e sedimentos, conforme evidenciado pelo grande estímulo da degradação anaeróbia de benzeno em sedimentos, na zona de redução de $\mathrm{Fe}^{3+}$ de um aquífero contaminado por derrame de petróleo. ${ }^{29}$

\section{MECANISMO DA TRANSFERÊNCIA DE ELÉTRONS OU MECANISMO BIOLÓGICO}

Os micro-organismos podem transferir os elétrons para o ânodo por três mecanismos: transferência direta das enzimas respiratórias (citocromos) para o eletrodo, através de mediadores externos à célula, introduzidos no meio em que os micro-organismos se encontram (ferricianeto de potássio, tionina), e ainda mediadores produzidos pela própria bactéria. ${ }^{25,26}$

A transferência de elétrons para o ânodo pode ser feita de maneira direta ou indireta. ${ }^{30} \mathrm{~A}$ transferência direta requer contato físico dos micro-organismos com o ânodo na célula. Em muitos casos os micro-organismos se desenvolvem em colônia sobre a superfície do ânodo na forma de um biofilme. ${ }^{31}$ Shewanella putrefaciens, Geobacter sulfurreducens, Geobacter metallireducens e Rhodoferax ferrireducens já foram classificados como micro-organismos capazes de gerar corrente elétrica em MFCs do tipo sem mediador, desenvolvendo colônias sobre o eletrodo. ${ }^{27,31}$ As bactérias presentes em MFCs sem mediadores possuem enzimas redox eletroquimicamente ativas em suas membranas, as quais transferem os elétrons para materiais externos, sem a necessidade de exógenos químicos para acompanhar a transferência de elétrons até o eletrodo. ${ }^{30}$ Quando estas bactérias oxidam o material orgânico presente, os elétrons são transferidos para o ânodo e os prótons sofrem difusão no meio até encontrar o contraeletrodo. Oxigênio e prótons são então cataliticamente reunidos para a formação de $\mathrm{H}_{2} \mathrm{O}$ no compartimento catódico, como demonstrado anteriormente. ${ }^{7,31}$

O mecanismo de transferência direta é extremamente elegante e atraente, no entanto, esta necessidade de contato físico entre eletrodo e micro-organismo é uma limitação para a obtenção de densidades de corrente maiores. Como exemplo, baixas densidades de corrente, da ordem de $3 \mathrm{~A} \mathrm{~cm}^{-2}$, foram citadas para uma MFC baseada na formação de biofilme de micro-organismos redutores de $\mathrm{Fe}^{3+}$ Rhodoferax ferrireducens. ${ }^{12}$

Outras espécies de bactérias incapazes de realizar esta transferência direta, ou simplesmente fora de contato físico com o ânodo, devido, por exemplo, ao aumento na espessura do biofilme, podem realizar um mecanismo de transferência indireto, através de "carregadores" de elétrons. Estes mediadores podem captar os elétrons da célula ao entrar em contato com esta, reduziremse, e então tornar ao estado oxidado, ou "estado natural" através do contato com os eletrodos, quando então o ciclo é reiniciado. Já foi reportado um importante papel de "nanofios" produzidos pelas bactérias para o último caso. ${ }^{19}$ Por sua vez, estes mediado- res podem ser naturais, produzidos pelas próprias bactérias, ou artificiais, introduzidos no meio. O uso de mediadores artificiais está sendo abandonado, ${ }^{32}$ devido à necessidade de reposição destes nas células e também pela geração de resíduos tóxicos, mas substâncias sintetizadas naturalmente pelas células podem atuar como carregadores de elétrons,${ }^{33}$ como é o caso da psicocianina e compostos correlatos produzidos por Pseudomas aeroginosa, ${ }^{34,35} \mathrm{e}$ também os nanofios, que foram relatados para ambas as espécies Geobacter e Shewanella. Pesquisas mostram que a redução do íon férrico por bactérias da espécie Shewanella também envolve mediadores ligados à membrana da célula, através da identificação de proteínas envolvidas na redução mineral dos óxidos férricos, presentes na membrana plásmatica, periplasma e outras membranas. Esta identificação foi feita por mutagenese ${ }^{36-38}$ e por estudos bioquímicos. ${ }^{38,39}$

Apesar dos resultados acima, o conhecimento da transferência de elétrons ainda é insuficiente para descobrir como as bactérias colonizam a superfície dos eletrodos e mantêm MFCs viáveis.

\section{Nanofios em bactérias}

Em 2005, Gorby e colaboradores relataram, através de estudos por microscopia de tunelamento por varredura (STM), a ocorrência de "prolongamentos" condutores para as espécies Geobacter e Shewanella. ${ }^{40}$ Quase simultaneamente foi demonstrada a existência de nanofios, que foi o termo criado por Gorby para G. Sulfurreducens, utilizando outras técnicas de detecção. ${ }^{19}$

Já há evidências da transferência eletrônica entre espécies diferentes de micro-organismos. Foi observado que bactérias da espécie Pelotomaculum thermopropionicum produzem minúsculas terminações condutoras que se assemelham a apêndices filiformes (forma de pelos). ${ }^{40} \mathrm{Em}$ culturas mistas, observou-se que as terminações podem conectar bactérias fermentativas a outras bactérias metanogênicas (M. Thermoautotrophicus).$^{40}$ Essas conexões podem facilitar a transferência de elétrons entre as bactérias fermentativas, as quais necessitam recuperar esses elétrons para regenerar o NADH intracelular. Normalmente, as bactérias fermentativas transferem os elétrons na formação de gás hidrogênio, ou através da produção de outras espécies reduzidas. Entretanto, a existência de terminações condutivas possibilita a transferência de elétrons diretamente de um micro-organismo a outro. Claramente, são necessários maiores estudos para verificar este interessante fenômeno.

\section{MEDIADORES QUÍMICOS}

Mediadores químicos ou "carregadores" de elétrons foram rotineiramente adicionados às MFCs para aperfeiçoar a captação dos elétrons do ciclo de oxidação. Uma variedade de produtos químicos tem sido usada para facilitar a rota dos elétrons de dentro da célula até os eletrodos. Estes mediadores incluem, por exemplo, neutral $r e d,{ }^{41}$ 2-6 dissulfato-antraquinona (AQDS), tionina, ferricianeto de potássio, ${ }^{7}$ violeta de metila , entre outros. ${ }^{11,39}$

Há casos onde os mediadores externos não precisam ser adicionados à cultura, devido à existência de mediadores químicos endógenos. ${ }^{38} \mathrm{~A}$ produção de altas concentrações de mediadores por culturas mistas contendo $P$. aeroginosa numa MFC de resistência interna muito baixa através do uso de ferricianeto como aceitador de elétrons produziu densidade de energia de 3,1 até 4,2 W/m. ${ }^{42} \mathrm{Em}$ sistema de fluxo contínuo, ou em sistemas nos quais a solução é trocada após cada ciclo de geração de energia quando o substrato é exaurido, é difícil acumular altas concentrações de mediadores. No entanto, Rabaey e seus colaboradores adicionaram substrato ao reator sem trocar a solução do compartimento anódico, o que possibilitou aumentar a concentração destes mediadores. ${ }^{33}$ 


\section{TIPOS DE MFCS}

Quatro configurações básicas para os bioreatores podem ser distinguidos nas MFCs:

\section{MFC de biorreator desacoplado}

Há produção microbiológica de hidrogênio ou metano, com subsequente recuperação em um biorreator separado procedido por uma célula de combustível química, geralmente operando a altas temperaturas, para converter o gás hidrogênio em eletricidade.

\section{MFC de biorreator integrado}

Há produção microbiológica de hidrogênio e conversão em eletricidade em apenas uma célula.

\section{MFC com transferência direta de elétrons}

Há geração de eletricidade com o uso de micro-organismos e transferência direta do elétron para o ânodo.

\section{MFC com mediador para a transferência de elétrons}

Há geração de eletricidade através dos micro-organismos e transferência do elétron para o ânodo por meio de um "carregador" de elétrons funcionando como mediador.

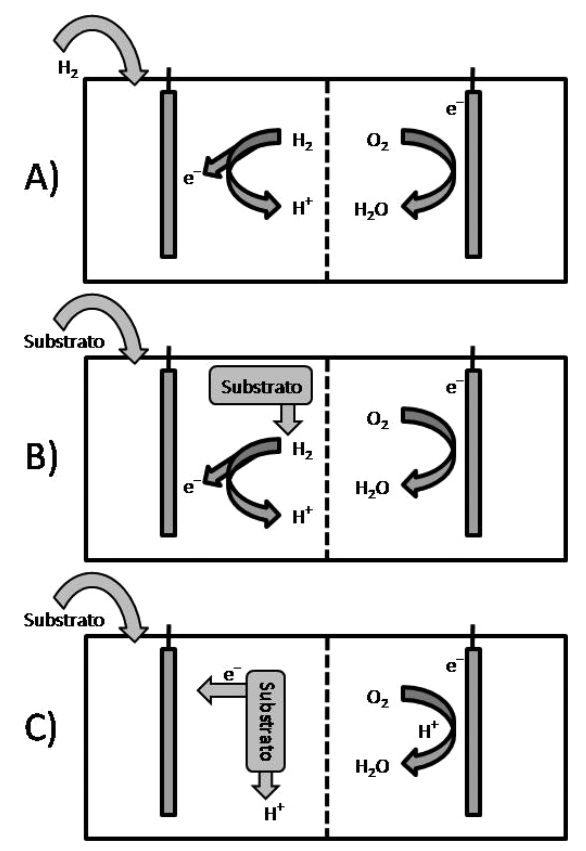

Figura 2. Configurações típicas para as MFCs. (A) MFC de biorreator desacoplado em um biorreator seguido por uma célula de combustível química. (B) MFC de biorreator acoplado. (C) MFC com interação ânodo-bactéria

\section{Fatores que influenciam o rendimento das MFCs}

O desempenho das MFCs pode ser influenciado por vários fatores. Dentre eles, as constantes de oxidação e transferência do elétron dos micro-organismos para o eletrodo, a resistência do circuito, transporte do próton para o cátodo através da membrana, e o fornecimento de oxigênio e a sua redução no cátodo. ${ }^{43}$ No estudo de Kim e seus colaboradores, foi feita a tentativa de otimização das condições acima. Observações por microscopia eletrônica mostraram a formação de um grosso biofilme de micro-organismos no ânodo da célula combustível, em aglomerações fracamente associadas ao eletrodo. ${ }^{17}$

Desde que o micro-organismo atue como catalisador na transferência de elétrons do substrato para o ânodo, a seleção de consórcio de micro-organismos de alto desempenho, seja cultura pura ou mista, é de crucial importância nas MFCs.

\section{POTENCIAIS APLICAÇÕES DAS MFCS}

\section{Sensores ambientais}

O conteúdo de material orgânico em uma solução é normalmente avaliado em função da demanda bioquímica de oxigênio (DBO). Os métodos clássicos para a determinação da DBO demoram de 5 (DBO5) a 7 (DBO7) dias de incubação em recipiente ao abrigo da luz. ${ }^{47}$ DBO5 e DBO7 são bons métodos para avaliação da qualidade de águas e esgotos, são baratos e aplicáveis a uma ampla faixa de amostras, no entanto, o tempo de análise os torna tediosos e demorados para a obtenção de resultados reprodutíveis. O princípio das MFCs pode ser aplicado à construção de biossensores para determinação rápida da $\mathrm{DBO}$, com os micro-organismos atuando como sensores e a corrente elétrica ou potencial gerado atuando como indicadores. Já foi desenvolvido um biossensor no qual micro-organismos atuam como catalisadores da oxidação de material orgânico, transferindo elétrons para o ânodo. ${ }^{41} \mathrm{~A}$ resposta do sensor construído mantevese linear até a concentração de $25 \mathrm{~g} \mathrm{~L}^{-1}$, com limite de detecção de $0,0025 \mathrm{~g} \mathrm{~L}^{-1}$ de glicose.

\section{Tratamento de resíduos agroindustriais}

Um modo de diminuir os custos do tratamento de esgoto animal e industrial é gerando quantidades apreciáveis de bioenergia, na forma de gás hidrogênio ou metano, a partir da matéria orgânica contida no esgoto, através de algum tratamento acoplado. ${ }^{10,38} \mathrm{O}$ processamento de águas residuais, para a produção de hidrogênio foi testado usando bactérias fermentativas em vários tipos de processos. ${ }^{41,44-46}$ Entretanto, estes processos não têm sido muito utilizados, devido à baixa recuperação de energia da matéria orgânica (1,4 -2,5 mols de hidrogênio por mol de hexose) e elevados custos operacionais. ${ }^{11,46}$

Efluentes provenientes das indústrias de processamento de alimentos ou vindos da pecuária de animais em regime de confinamento são poluentes ambientais ideais para o bioprocessamento, pois contêm altos níveis de material orgânico facilmente degradável, cujo resultado é um saldo positivo de energia ao final do processo. Como efluentes são fontes potenciais de energia, a recuperação desta ou a transformação destes efluentes em subprodutos úteis pode reduzir o custo do tratamento e, em alguns casos, diminuir também a nossa dependência dos combustíveis fósseis.

\section{Geração de energia elétrica}

A produção de energia na forma de eletricidade é a aplicação mais óbvia e direta das MFCs. Conforme já citado, essas células podem funcionar como fontes de energia autossustentáveis por longos períodos de tempo em áreas remotas, fornecendo energia elétrica in situ para pequenos aparatos elétricos, como sensores on line e transmissores de dados, por exemplo, em alto mar. Para contornar o problema de tensão e corrente elétrica baixas, capacitores e conversores podem ser utilizados ${ }^{50}$ Este princípio foi recentemente demonstrado com uma SMFC (MFC do tipo sedimentar), que manteve em funcionamento um sensor meteorológico e seu transmissor de dados, consumindo aproximadamente $18 \mathrm{~mW}$. Isto foi possível graças à aplicação de um estabilizador de voltagem e um capacitor. ${ }^{27}$ 
A produção de cerveja consome grandes quantidades de água, utilizando aproximadamente $7 \mathrm{~L}$ de água para cada litro de cerveja produzido. ${ }^{47}$ Geralmente, essa água é usada nas atividades de lavagem e o esgoto é tratado antes de ser descartado no meio ambiente. A reutilização desta água não é comum neste tipo de indústria devido a problemas de aceitação pública e possível deterioração da qualidade do produto final. O tratamento e disposição corretos destes rejeitos são um sério problema ambiental. Este tipo de resíduo não é muito tóxico, mas possui elevados valores de DQO e DBO, quando comparado a outros tipos de esgotos industriais. Geralmente, são adotados métodos biológicos para o tratamento deste tipo de esgoto, com objetivo de diminuir a DQO. ${ }^{48,49}$

O principal problema destes tratamentos é a alta quantidade de energia gasta, consumida principalmente nos processos de aeração do resíduo. Devido a isto e ao aumento da rigidez das leis de tratamento e disposição de resíduos, alternativas estão sendo estudadas para reduzir, reciclar e recuperar energia destes esgotos, dentre os quais se destaca a utilização em MFCs, por seus elevados teores de DQO e DBO.

\section{MFCs para tratamento de esgoto}

As MFCs formam uma promissora tecnologia para o tratamento de esgotos, como um método de recuperar energia na forma de hidrogênio ou eletricidade, ao mesmo tempo em que se produzem condicionadores orgânicos de solos para a agricultura. Na década de 90, Kim e seus colaboradores demonstraram que as bactérias podem ser usadas como maneira de se determinar a concentração de lactato em solução ${ }^{30}$ e que uma MFC pode ser sustentada por resíduos industriais. Entretanto, a quantidade de energia produzida foi baixa e não ficou claramente definido que o uso das MFCs pode reduzir significativamente o nível de material orgânico no esgoto utilizado. Em 2004, houve uma mudança na relação entre produção de energia elétrica e tratamento de esgoto, quando foi demonstrado que esgoto doméstico pode ser tratado em níveis práticos paralelamente à geração de energia elétrica. ${ }^{50} \mathrm{~A}$ quantidade de energia gerada no estudo, apesar de baixa, pode ser considerada alta em relação aos estudos anteriores. Reimers, em 2001, demonstrou que os materiais orgânicos e inorgânicos presentes em sedimentos marinhos podiam ser usados em um novo tipo de MFCs, com o uso de variedade de substratos, materiais e novos arranjos estruturais na construção das MFCs. ${ }^{51}$

\section{CONCLUSÕES}

Embora seja uma tecnologia ainda na fase inicial de desenvolvimento, as células de combustíveis baseadas em micro-organismos podem se tornar alternativa viável para a geração de energia elétrica, ao mesmo tempo em que promovem o tratamento de rejeitos orgânicos municipais e agroindustriais. Considerando-se a quantidade de rejeitos orgânicos gerados no Brasil, pode-se pensar nas MFCs como mais uma forma de transformar a energia solar, abundante em nosso país, em energia elétrica. Simultaneamente serão produzidos, como subprodutos das MFCs, condicionadores orgânicos de solos, tão necessários para melhorar a estrutura e a produção e produtividade dos intemperizados solos brasileiros.

\section{REFERÊNCIAS}

1. Potter, M. C.; Proc. R. Soc. Ser. 1912, B84, 260.

2. Galembeck, F.; Barbosa, C. A. S.; Sousa, R. A.; Quim. Nova 2009, 32, 571.

3. Katz, E.; Shipway, N.; Willner, I.; Vielstich, W.; Gasteiger, H. A.; Lamma, A.; Handbook of Fuel Cells - Fundamentals, Technology and Applications, Fundamentals and Survey of Systems, Wiley: New York, 2003.

4. Lewis, N. S.; Nocera, D. G.; Proc. Natl. Acad. Sci. U. S. A. 2006, 103, 15729
5. Rifkin, J.; The Hydrogen Economy, Tarcher/Putnam: New York, 2002.

6. Cohen, B.; J. Bacteriol. 1931, 121, 18.

7. Grzebyk, P.; Sep. Purif. Technol. 2004, 41, 321.

8. Jang, J. K.; Pham, T. H.; Chang, I. S.; Kang, K. H.; Moon, H.; Cho, K. S.; Kim, B. H.; Process Biochem. 2004, 39, 1007.

9. Kim, B. H.; Park, H. S.; Kim, K. J.; Kim, G. T.; Chang, I. S.; Lee, J.; Phung, N. T.; Appl. Microbiol. Biotechnol. 2004, 63, 672.

10. Liu, H.; Logan, B. E.; Environ. Sci. Technol. 2004, 38, 4040.

11. Logan, B. E.; Nat. Rev. Microbiol. 2009, 7, 375.

12. Bond, D. R.; Lovley, D. R.; Appl. Environ. 2003, 69, 1548.

13. Chaudhuri, S. K.; Lovley, D. R.; Nat. Biotechnol. 2003, 21, 1229.

14. Min, B.; Kim, J. R.; Oh, S.; Regan, J. M.; Logan, B. E.; Water Res. 2005, 39, 4961 .

15. Ieropoulos, I. A.; Greenman, J.; Melhuish, C.; Hart, J.; Enzyme Microb. Technol. 2005, 37, 238.

16. Niessen, J.; Schröder, U.; Rosenbaum, M.; Scholz, F.; Eletrochem. Commun. 2004, 6, 571 .

17. Mathuriya, A. S.; Sharma, V. N.; J Biochem Tech. 2009, 1(2), 49.

18. Gil, G. C.; Chang, I. S.; Kim, B. H.; Kim, M.; Jang, J. K.; Biosens. Bioelectron. 2003, 18, 327.

19. Logan, B. E.; Microbial Fuel Cells, Wiley: New York, 2003.

20. Rohrback, G. H.; Scott, W. R.; Canfield, J. H.; Proceedings of the $16^{\text {th }}$ Annual Power Sources Conference, Fort Monmouth, USA, 1962.

21. Williams, K. R.; An Introduction to Fuel Cells, Elsevier: Amsterdam, 1966.

22. Yao, S. J.; Appleby, A. J.; Geise, A.; Cash, H. R.; Wolfson, S. K.; Nature 1969, 224, 921.

23. Karube, I.; Ikemoto, H.; Kajiwara, K.; Tamiya, E.; Matsuok, H.; BioTechnology 1986, 4, 73.

24. Lovley, D. R.; Nat. Rev. Microbiol. 2006, 4, 497

25. Sisler, F. D.; J. Wash. Acad. Sci. 1962, 52, 182.

26. Wilkinson, S.; Autonomous Robots 2000, 9, 99

27. Tender, L. M.; Reimers, C. E.; Stecher, H. A.; Holmes, D. E.; Bond, D. R.; Lowy, D. A.; Pilobello, K.; Fertig, S. J.; Lovley, D. R.; Nat. Biotechnol. 2002, 20, 821 .

28. Lovley, D. R.; Woodward, J. C.; Chapelle, F. H.; Appl Environ. Microbiol. 1996, 62, 288.

29. Mangrich, A. S.; Silva, L. da; Pereira, B. F.; Messerschmidt, I.; J. Braz. Chem. Soc. 2009, 294, 20.

30. Kim, B. H.; Kim, H. J.; Hyun, M. S.; Park, D. H.; J. Microbiol. Biotechnol. 1999, 9, 365.

31. Pham, C. A.; Jung, S. J.; Phung, N. T.; Lee, J.; Chang, I. S.; Kim, B. H.; Yi, H.; Chun, J.; FEMS Microbiol. Lett. 2003, 129, 223

32. Rosenbaum, M.; Zhao, F.; Schrder, U.; Scholz, F.; Appl. Catal., B 2006, 74, 262.

33. Rabaey, K.; Boon, N.; Siciliano, S. D.; Verhaege, M.; Verstraete, W.; Appl. Environ. Microbiol. 2004, 70, 5373.

34. Niessen, J.; Harnisch, F.; Rosenbaum, M.; Schröder, U.; Scholz, F.; Electrochem. Commun. 2006, 8, 869.

35. Rabaey, K.; Boon, N.; Verstraete, W.; Höfte, M.; Environ. Sci. Technol. 2005, 39, 3401.

36. Clauwaert, P.; Verstraete, W.; Appl. Microbiol. Biotech. 2008, 82, 829.

37. Beliaev, A. S.; Saffarini, D. A.; J. Bacteriol. 1998, 180, 6292.

38. Myers, J. M.; Myers D. R.; J. Bacteriol. 2000, 182, 67.

39. Myers, J. M.; Myers D. R.; J. Bacteriol. Appl. Environ. Microbiol. 2001, $67,260$.

40. Gorby, Y. A.; Beveridge, T. J.; William, R. W.; Abstracts of the $18^{\text {th }}$ Anual Conference NABIR PI Meeting, Warrenton, USA, 2005.

41. Kumlanghan, A.; Liu, J.; Thavarungkul, P.; Liu, J.; Kanatharana, P.; Mattiasson, B.; Biosens. Bioelectron. 2007, 22, 2939.

42. Clauwaert, P.; Van der Ha, D.; Verstraete, W.; Biotechnol. Lett. 2008, 30, 1947.

43. Liu, H.; Logan, B. E.; Environ. Sci. Technol. 2004, 39, 4317 
44. Oh, S. E.; Logan, B. E.; Water Res. 2005, 39, 4673.

45. Das, D.; Veziroglu T. N.; Int. J. Hydrogen Energy 2001, 26, 13.

46. Yu, X.; Amrhein, C.; Deshusses, M. A.; Matsumoto, M. R.; Environ. Sci. Technol. 2006, 40, 1328.

47. Janhom, T.; Wattanachira, S.; Pavasant P.; J. Environ. Monit. 2009, 90, 1184.

48. Ince, B. K.; Ince, O.; Sallis, P. J.; Anderson, G. K.; Water Res. 2000, 34, 3943.
49. Parawira, W.; Murto, M.; Read, J. S.; Mattiasso, B.; Process Biochem. 2005, 40, 2945.

50. Liu, H.; Ramnarayanan, R.; Logan, B. E.; Environ. Sci. Technol. 2004, $38,2281$.

51. Reimers, C. E.; Tender, L. M.; Fertig, S.; Wang, W.; Environ. Sci. Technol. 2001, 35, 192. 